\title{
Penentuan Status Mutu Air Metode Storet DAS Kali Curah Macan
}

\section{Determination of Water Quality Status of the Storet Method of Curah Macan River}

\author{
Saiful Anwar ${ }^{1)}$ Budi Hariono $^{2)}$, Michael Joko Wibowo ${ }^{2)}$, Merry Muspita Dyah Utami ${ }^{3)}$ \\ ${ }^{1}$ Jurusan Teknologi Pertanian, Politeknik Negeri Jember, Jl. Mastrip PO Box 164, Jember, 68121 \\ ${ }^{2}$ Jurusan Teknik, Politeknik Negeri Jember, Jl. Mastrip PO Box 164, Jember, 68121 \\ ${ }^{3}$ Jurusan Peternakan, Politeknik Negeri Jember, Jl. Mastrip PO Box 164, Jember, 68121 \\ Email: budihariono1966@gmail.com
}

\begin{abstract}
The monitoring station of Curah Macan Watershed is located in Arjasa Village, Arjasa District, Situbondo Regency with $7^{\circ} 71^{\prime} 66^{\prime \prime}$ at the South Latitude and $114^{\circ} 12^{\prime} 17^{\prime \prime}$ at the East Longitude. The aim research is to know the quality of water routinely, so that the water quality condition of river water body can be detected from the beginning. This is due to changes in land functions that have reduced water absorption function, erosion, sedimentation and industrial and household activities. Therefore, research on the analysis of the status of water quality especially in the Curah Macan watershed is very important to be done periodically in order to maintain its sustainability. The research using STORET method shows the water quality of Curah Macan watershed in the period of January - December 2017 for the quality of class I, II, III and IV has a score respectively $-50 ;-28 ;-12$ and -4 so that the water quality qualification is bad, moderate, moderate and good.
\end{abstract}

Keyword : Kali Macan Watershed, Storet Method, Water Quality, Period January - December 2017

\section{PENDAhuluan}

DAS Sungai Kali Curah Macan merupakan salah satu dari 9 DAS yang berada dalam pengelolaan Balai Pengelolaan Sumber Daya Air Wilayah Sungai Sampean Baru di Bondowoso. Keseluruhan DAS tersebut meliputi : (1) Kali Sampean; (2) Kali Deluwang; (3) Kali Lobawang; (4) Kali Tlogo/Ampel; (5) Kali Curah Macan; (6) Kali Baru; (7) Kali Bomo; (8) Kali Tambong dan (9) Kali Bajulmati. Stasiun pantau Kali Curah Macan sebanyak 1 buah terdapat di Desa Arjasa Kecamatan Arjasa Kabupaten Situbondo dengan $7^{\circ} 71^{\prime} 66^{\prime}$ "Lintang Selatan dan $114^{\circ} 12^{\prime} 17^{\prime}$ "Bujur Timur.

Secara umum kondisi DAS di Indonesia terdapat beberapa permasalahan, antara lain (a) penggunaan kebutuhan pertanian, perkebunan, industri dan masyarakat semakin meningkat, (b) fluktuatifnya ketersediaan air pada saat musim penghujan dan kemarau, (c) pemanfaatan yang berlebihan (over exploited) tanpa memperhatikan daya dukung, (d) erosi meningkat serta (e) pencemaran air yang tidak terkontrol (Walukow, 2010).
Bahan polutan dari pertanian, perkebunan, industri dan masyarakat dapat menimbulkan kerugian, bilamana jumlahnya melebihi ambang normal, keberadaannya pada waktu dan tempat yang tidak tepat. Sifat dapat merusak sementara serta dalam waktu lama (Walukow, 2010).

Menurut Taufik (2003) beberapa jenis polutan dari aktifitas pertanian adalah pestisida, bahan beracun, dan logam berat. Polutan dari aktifitas peternakan adalah BOD, COD, TOC, $\mathrm{pH}$, suspended solid, klorida, nitrat, fosfor, warna, bahan beracun, suhu dan kekeruhan. Polutan dari aktifitas perkebunan adalah $\mathrm{COD}, \mathrm{pH}$, suspended solid, TDS, minyak dan lemak, kromium, kalsium, klorida, sulfat, amoniak, sodium, nitrat, fosfor, urea anorganik, coli faeces dan suhu. Polutan dari aktifitas pemukiman masyarakat adalah Deterjen, zat padat, BOD, COD, TOD, TOC, nitrogen, fosfor, kalsium, klorida dan sulfat. Polutan dari aktifitas aneka industri adalah BOD, $\mathrm{pH}$, suspended solid, settleable solid, TDS, minyak dan lemak, warna, jumlah coli, bahan beracun, suhu, kekeruhan, amoniak dan kekeruhan. Pencemaran tersebut menyebabkan kualitas atau mutu air dari DAS 
berkurang atau tidak dapat berfungsi lagi sesuai dengan peruntukannya (UU Pokok Pengelolaan Lingkungan Hidup No. 4 Tahun 1982).

Rumusan penelitian ini mengetahui perkembangan kondisi mutu air sungai di DAS Kali Curah Macan disesuaikan dengan syarat mutu air. Tujuan penelitian adalah menentukan kondisi mutu air sungai DAS Kali Curah Macan dalam rangka mendukung kehidupan masyarakat. Sebagai gambaran status mutu air salah satu DAS di bawah pengelolaan Balai Pengelolaan Sumber Daya Air Wilayah Sungai Sampean Baru Bondowoso yaitu DAS Kalibaru pada periode 2016 untuk mutu kelas I, II, III dan IV menggunakan metode Storet berturut-turut adalah sedang, sedang, baik dan baik (Hariono et al., 2017), sedangkan Sugiyarto et al., (2017) juga menyatakan pemantauan kualitas air di DAS Sampean menggunakan metode NSF-IKA menunjukkan kualitas air di sungai Sampean adalah kategori menengah. Mengacu pada kondisi di atas, maka penelitian status mutu air DAS Kali Curah Macan penting dilakukan untuk mengetahui kualitas mutu air.

\section{METODE PENELITIAN}

Stasiun pengamatan dilakukan di pos pengamatan Desa Arjasa Kecamatan Arjasa Kabupaten Situbondo. Parameter yang diukur meliputi sifat fisik, kimia dan mikrobiologi. Datadata masing-masing parameter dari bulan Januari hingga Desember 2017 berasal dari Balai Pengelolaan Sumber Daya Air Wilayah Sungai Sampean Baru di Bondowoso, selanjutnya dibandingkan dengan data standar baku mutu air I, II, III dan IV.
PP 82 Tahun 2001 menetapkan klasifikasi mutu air menjadi 4 (empat) kelas, yaitu: (1) Kelas I, untuk bahan baku air minum, dan atau peruntukan lain yang mempersyaratkan mutu air yang sama dengan kegunaan tersebut; (2) Kelas II, untuk prasarana/sarana rekreasi air, pembudidayaan ikan air tawar, peternakan, air untuk mengairi pertanaman, dan atau peruntukan lain yang mempersyaratkan mutu air yang sama dengan kegunaan tersebut; (3) Kelas III, untuk pembudidayaan ikan air tawar, peternakan, air untuk mengairi pertanaman, dan atau peruntukan lain yang mempersyaratkan air yang sama dengan kegunaan tersebut; serta (4) Kelas empat, untuk mengairi, pertanaman dan atau peruntukan lain yang mempersyaratkan mutu air yang sama dengan kegunaan tersebut.

Metode yang digunakan dalam mengukur sifat fisik, kimia dan mikrobiologis tertera pada Tabel 1. Penentuan status mutu air metode Storet dilakukan dengan tahapan: (1) membandingkan hasil pengukuran sampel dengan nilai baku mutu sesuai dengan kelas mutu air; (2) bila nilai hasil pengukuran memenuhi nilai baku mutu (nilai hasil pengukuran < baku mutu) maka diberi skor 0, (3) bila hasil pengukuran tidak memenuhi standar baku mutu air (nilai hasil pengukuran > baku mutu) maka diberi skor. Dalam penelitian ini menggunakan sampel contoh pada masing-masing stasiun pengamatan sebanyak 3 sampel $(<10$ jumlah sampel) sehingga penilaian seperti tertera pada Tabel 2.

\begin{tabular}{|c|c|c|c|c|c|c|c|c|}
\hline No. & Parameter & Satuan & $\begin{array}{c}\text { Baku Mutu } \\
\text { I }\end{array}$ & $\begin{array}{c}\text { Baku Mutu } \\
\text { II }\end{array}$ & $\begin{array}{c}\text { Baku Mutu } \\
\text { III }\end{array}$ & $\begin{array}{c}\text { Baku } \\
\text { Mutu IV }\end{array}$ & Model Analitis & Peralatan \\
\hline & FISIKA & & & & & & & \\
\hline 1 & Temperatur & ${ }^{\circ} \mathrm{C}$ & normal \pm 3 & normal \pm 3 & normal \pm 3 & $\begin{array}{c}\text { normal } \\
3\end{array}$ & $\begin{array}{l}\text { Pengukuran } \\
\text { temperatur }\end{array}$ & Termometer \\
\hline \multirow[t]{2}{*}{2} & TSS & $\mathrm{mg} / \mathrm{L}$ & 1000 & 1000 & 1000 & 1000 & Gravimetri & Timbangan analitik \\
\hline & KIMIA & & & & & & & \\
\hline 1 & $\mathrm{pH}$ & - & 6 sd 9 & $5 \mathrm{~s} / \mathrm{d} 9$ & 5 s/d 9 & 5 sd 9 & Potensiometer & $\mathrm{pH}$ meter \\
\hline 2 & BOD & $\mathrm{mg} / \mathrm{L}$ & 2 & 3 & 6 & 12 & Open reflux & Kolom destilasi \\
\hline 3 & COD & $\mathrm{mg} / \mathrm{L}$ & 10 & 25 & 50 & 100 & Open reflux & Kolom destilasi \\
\hline 4 & DO & $\mathrm{mg} / \mathrm{L}$ & 6 & 4 & 3 & $<3$ & Potensiometer & DO meter \\
\hline 5 & PO4-P & $\mathrm{mg} / \mathrm{L}$ & 0,2 & 0,2 & 1 & 5 & Spektrometri & Spektrometeri vis \\
\hline 6 & NO3-N & $\mathrm{mg} / \mathrm{L}$ & 10 & 10 & 20 & 20 & Spektrometri & Spektrometeri vis \\
\hline \multirow[t]{2}{*}{7} & NH3-N & $\mathrm{mg} / \mathrm{L}$ & 0,5 & 0,5 & 0,02 & 0,02 & Spektrometri & Spektrometeri vis \\
\hline & MIKROBIOLOGI & & & & & & & \\
\hline 1 & Total Coli & $\mathrm{jml} / 100 \mathrm{ml}$ & 5000 & 5000 & 5000 & 5000 & Metode MPN & \\
\hline \multirow[t]{2}{*}{2} & Fecal Coliform & $\mathrm{jml} / 100 \mathrm{ml}$ & 5000 & 5000 & 5000 & 5000 & Metode MPN & \\
\hline & KIMIA ORGANIK & & & & & & & \\
\hline 1 & Minyak \& Lemak & $\mathrm{mg} / \mathrm{L}$ & & & & 0,5 & & \\
\hline 2 & Phenol & $\mathrm{mg} / \mathrm{L}$ & & & & 0,001 & & \\
\hline
\end{tabular}


TABEL 2

Penentuan Sistem Nilai Untuk Menentukan Status MUTU AIR (CANTER, 1977)

\begin{tabular}{|c|c|c|c|c|}
\hline \multirow{2}{*}{$\begin{array}{l}\text { Jumlah } \\
\text { contoh }\end{array}$} & \multirow{2}{*}{ Nilai } & \multicolumn{3}{|c|}{ Parameter } \\
\hline & & Fisika & Kimia & Biologi \\
\hline \multirow[t]{3}{*}{$<10$} & Maksimum & -1 & -2 & -3 \\
\hline & Minimum & -1 & -2 & -3 \\
\hline & Rata-rata & -3 & -6 & -9 \\
\hline
\end{tabular}

\section{HASIL DAN PEMBAHASAN}

Perhitungan status mutu air DAS Kali Curah Macan untuk mutu kelas I, II, III dan IV berturutturut mempunyai skor $-50 ;-28 ;-12$ dan -4 sehingga kulifikasi mutu airnya berturut-turut dinyatakan buruk, sedang, sedang dan baik (tertera Tabel 3). Berdasarkan Tabel 5, tinggi rendahnya skor mutu air DAS Curah Macan dipengaruhi aktivitas cemaran kimia seperti : BOD, $\mathrm{NH}_{3} \mathrm{~N}, \mathrm{NO}_{2} \mathrm{~N}, \mathrm{COD}, \mathrm{DO}$, dan $\mathrm{PO}_{4} \mathrm{P}$ dengan nilai total cemaran berturut-turut -28, -
$24,-14,-12,-10$ dan -4 . Hal ini memperlihatkan bahwa cemaran diakibatkan aktivitas aneka industri (industrial wastes), pemukiman (sewage), peternakan dan perkebunan (agriculture wastes) di sepanjang DAS Kali Curah Macan. Bahan pencemar utama DAS Kali Curah Malang berupa berupa pestisida, organisme eksotik, organisme patogen, sampah dan oxygen depleting substance (bahan yang menyebabkan oksigen terlarut berkurang). Pencemaran limbah domestik dapat diketahui dari tingginya nilai nitrat dan fosfat. Menurut Effendi (2003), keberadaan fosfat berlebih mampu menstimulasi eutrofikasi (pengayaan) perairan yang menyebabkan perairan menjadi lunak (soft water) dan kurang produktif.

Hasil perhitungan kualitas mutu air DAS Sungai Kali Curah Macan periode Januari Desember 2017 dengan metode STORET tertera pada Tabel 3.

Tabel 3. Kualitas Mutu Air Das Kali Curah Macan Periode Januari - Desember 2017

\begin{tabular}{|c|c|c|c|c|c|c|c|c|c|c|c|c|c|}
\hline \multirow[b]{2}{*}{ No. } & \multirow[b]{2}{*}{ Parameter } & \multirow[b]{2}{*}{ Satuan } & \multirow{2}{*}{$\begin{array}{c}\text { Baku } \\
\text { Mutu I }\end{array}$} & \multirow{2}{*}{$\begin{array}{c}\text { Baku } \\
\text { Mutu II }\end{array}$} & \multirow{2}{*}{$\begin{array}{c}\text { Baku } \\
\text { Mutu III }\end{array}$} & \multirow{2}{*}{$\begin{array}{c}\text { Baku } \\
\text { Mutu IV }\end{array}$} & \multicolumn{3}{|c|}{ Hasil Pengukuran } & \multirow{2}{*}{$\begin{array}{c}\text { SKOR } \\
\text { untuk } \\
\text { Mutu I }\end{array}$} & \multirow{2}{*}{$\begin{array}{c}\text { SKOR } \\
\text { untuk } \\
\text { Mutu II }\end{array}$} & \multirow{2}{*}{$\begin{array}{c}\text { SKOR } \\
\text { untuk } \\
\text { Mutu III }\end{array}$} & \multirow{2}{*}{$\begin{array}{c}\text { SKOR } \\
\text { untuk } \\
\text { Mutu IV }\end{array}$} \\
\hline & & & & & & & Mak & Min & Rata-rata & & & & \\
\hline & FISIKA & & & & & & & & & & & & \\
\hline 1 & Temperatur & ${ }^{\circ} \mathrm{C}$ & normal \pm 3 & normal \pm 3 & normal \pm 3 & normal \pm 3 & 24,800 & 23,300 & 24,050 & 0 & 0 & 0 & 0 \\
\hline \multirow[t]{2}{*}{2} & TSS & $\mathrm{mg} / \mathrm{L}$ & 1000 & 1000 & 1000 & 1000 & 189,000 & 7,600 & 98,300 & 0 & 0 & 0 & 0 \\
\hline & KIMIA & & & & & & & & & & & & \\
\hline 1 & $\mathrm{pH}$ & - & 6 sd 9 & $5 \mathrm{~s} / \mathrm{d} 9$ & $5 \mathrm{~s} / \mathrm{d} 9$ & $5 \mathrm{sd} 9$ & 8,400 & 5,700 & 7,050 & -2 & 0 & 0 & 0 \\
\hline 2 & BOD & $\mathrm{mg} / \mathrm{L}$ & 2 & 3 & 6 & 12 & 8,750 & 5,700 & 6,900 & -10 & -10 & -8 & 0 \\
\hline 3 & COD & $\mathrm{mg} / \mathrm{L}$ & 10 & 25 & 50 & 100 & 28,410 & 13,450 & 20,930 & -10 & -2 & 0 & 0 \\
\hline 4 & DO & $\mathrm{mg} / \mathrm{L}$ & 6 & 4 & 3 & $<3$ & 7,000 & 3,600 & 5,300 & -8 & -2 & 0 & 0 \\
\hline 5 & PO4-P & $\mathrm{mg} / \mathrm{L}$ & 0,2 & 0,2 & 1 & 5 & 0,247 & 0,049 & 0,148 & -2 & -2 & 0 & 0 \\
\hline 6 & NO3-N & $\mathrm{mg} / \mathrm{L}$ & 10 & 10 & 20 & 20 & 3,467 & 0,944 & 2,206 & 0 & 0 & 0 & 0 \\
\hline 7 & $\mathrm{NH} 3-\mathrm{N}$ & $\mathrm{mg} / \mathrm{L}$ & 0,5 & 0,5 & 0,02 & 0,02 & 0,146 & 0,001 & 0,074 & -10 & -10 & -2 & -2 \\
\hline 8 & $\mathrm{NO} 2-\mathrm{N}$ & $\mathrm{mg} / \mathrm{L}$ & 1,0 & 0,06 & 0,06 & 0,06 & 1,617 & 0,001 & 0,809 & -8 & -2 & -2 & -2 \\
\hline \multicolumn{3}{|c|}{ MIKROBIOLOGI } & & & & & & & & & & & \\
\hline 1 & TotalColi & $\mathrm{jml} / 100 \mathrm{ml}$ & 5000 & 5000 & 5000 & 5000 & 460,000 & 21,000 & 240,500 & 0 & 0 & 0 & 0 \\
\hline 2 & Fecal Coliform & $\mathrm{jml} / 100 \mathrm{ml}$ & 5000 & 5000 & 5000 & 5000 & 210,000 & 15,000 & 112,500 & 0 & 0 & 0 & 0 \\
\hline \multicolumn{3}{|c|}{ KIMIA ORGANIK } & & & & & & & & & & & \\
\hline 1 & Minyak \& Lemak & $\mathrm{mg} / \mathrm{L}$ & & & 0,5 & 0,5 & 0,500 & 1,900 & 1,900 & 0 & 0 & 0 & 0 \\
\hline 2 & Phenol & $\mathrm{mg} / \mathrm{L}$ & & & & 0,001 & 0,001 & 0,050 & 0,002 & 0 & 0 & 0 & 0 \\
\hline \multicolumn{14}{|c|}{ OGAM DAN OGAM BERAT } \\
\hline 1 & Krom & $\mathrm{mg} / \mathrm{L}$ & & 0,50 & 0,50 & & 0,088 & 0,088 & 0,088 & 0 & 0 & 0 & 0 \\
\hline 2 & Tembaga & $\mathrm{mg} / \mathrm{L}$ & 1,00 & 0,20 & 0,20 & & 0,020 & 0,020 & 0,020 & 0 & 0 & 0 & 0 \\
\hline & \multicolumn{9}{|c|}{ Indeks Pencemaran } & -50 & -28 & -12 & -4 \\
\hline
\end{tabular}


Mutu air DAS Kali Curah Macan yang dinilai menggunakan metode STORET rekomendasikan EPA (Environmental Protection Agency) terdapat empat kelas mutu air, yaitu:

(1) Kelas A: baik sekali, skor $=0$ memenuhi baku mutu air

(2) Kelas B : baik, skor $=-1 \mathrm{~s} / \mathrm{d}-10$ dengan tingkat cemar ringan

(3) Kelas C : sedang, skor $=-11 \mathrm{~s} / \mathrm{d}$ 30 dengan tingkat cemar sedang

(4) Kelas D: buruk, skor $=>-31$ dengan tingkat cemar berat.

TABEL 4

Status Mutu Air Sungai DAS Kali Curah Macan PERIODE JANUARI - DESEMBER 2017

\begin{tabular}{rcccc}
\hline DAS & \multicolumn{4}{c}{ Kualifikasi Mutu Air } \\
\cline { 2 - 5 } Kali & & & \multicolumn{3}{c}{ Kelas } \\
Curah & Kelas I & Kelas II & Kelas III & IV \\
\cline { 2 - 5 } Macan & buruk & sedang & sedang & baik \\
\hline Skore & -50 & -28 & -12 & -4 \\
\hline
\end{tabular}

\section{KESIMPULAN}

Perhitungan mutu air metode SORET, tingkat cemaran untuk mutu air I, II, III, dan IV berturutturut mempunyai skor $-50 ;-28 ;-12$; dan -4 atau kategori buruk, sedang, sedang dan baik. Kondisi ini mempunyai arti bahwa sebagai berikut:

1. air yang peruntukannya dapat digunakan untuk bahan baku air minum, dan atau peruntukan lain yang mempersyaratkan mutu air yang sama dengan kegunaan tersebut dinilai BURUK

2. air yang peruntukannya dapat digunakan untuk prasarana/sarana rekreasi air, pembudidayaan ikan air tawar, peternakan, air untuk mengairi pertanaman, dan atau peruntukan lain yang mempersyaratkan mutu air yang sama dengan kegunaan tersebut dinilai SEDANG.

3. air yang peruntukannya dapat digunakan untuk pembudidayaan ikan air tawar, peternakan, air untuk mengairi pertanaman, dan atau peruntukan lain yang mempersyaratkan air yang sama dengan kegunaan tersebut dinilai SEDANG.

4. air yang peruntukannya dapat digunakan untuk mengairi, pertanaman dan atau peruntukan lain yang mempersyaratkan mutu air yang sama dengan kegunaan tersebut dinilai BAIK.

\section{DAFTAR PUSTAKA}

[1] Canter, L. W. 1977. Environmental Impact Assesment. McGraw Hill Book Company. New York.

[2] Effendi, H. 2003. Telaah Kualitas Air Bagi Pengelolaan Sumber Daya Alam dan Lingkungan Perairan. Penerbit Kanisius. Yogyakarta.

[3] Hariono, B., Riskiawan, H.K., Sugiyarto, Anwar, S. (2017). Prosiding dari SENTRINOV: Penentuan Status Mutu Air Metode Storet DAS Kalibaru. Vol 3. ISSN: 2477-2097.

[4] Pemerintah Republik Indonesia. 2001. PP RI No. 82. Tentang Pengelolaan Kualitas Air dan Pengendalian Pencemaran Lingkungan.

[5] Sugiyarto, Hariono, B., Destarianto, P. (2017). Prosiding dari SENTRINOV: Dampak Perubahan Tata Guna Lahan Terhadap Kualitas Air Sungai Di DAS Sampean. Vol 3. ISSN: 2477-2097.

[6] Walukow, A.F. 2010. Penentuan Status Mutu Air Dengan Metode Storet Di Danau Sentani Jayapura Propinsi Papua. Berita Biologi 10 (3), $277-281$. 
